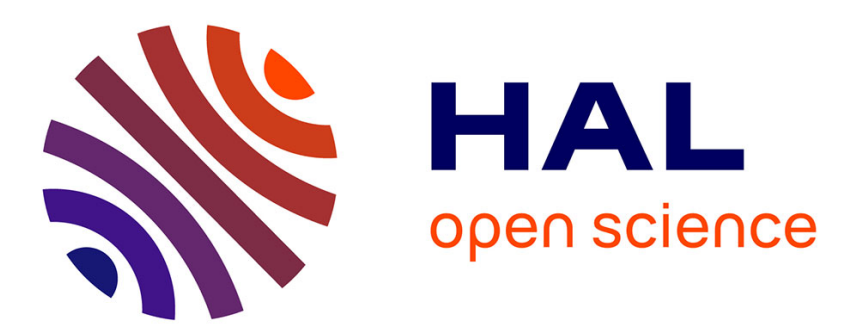

\title{
Renal injury at first presentation as a predictor for poor outcome in severe paracetamol poisoning referred to a liver transplant unit
}

\author{
N. Pakravan, K. J. Simpson, W. S. Waring, C. M. Bates, D. N. Bateman
}

\section{- To cite this version:}

N. Pakravan, K. J. Simpson, W. S. Waring, C. M. Bates, D. N. Bateman. Renal injury at first presentation as a predictor for poor outcome in severe paracetamol poisoning referred to a liver transplant unit. European Journal of Clinical Pharmacology, 2008, 65 (2), pp.163-168. 10.1007/s00228-0080580-9 . hal-00477933

\section{HAL Id: hal-00477933 \\ https://hal.science/hal-00477933}

Submitted on 30 Apr 2010

HAL is a multi-disciplinary open access archive for the deposit and dissemination of scientific research documents, whether they are published or not. The documents may come from teaching and research institutions in France or abroad, or from public or private research centers.
L'archive ouverte pluridisciplinaire HAL, est destinée au dépôt et à la diffusion de documents scientifiques de niveau recherche, publiés ou non, émanant des établissements d'enseignement et de recherche français ou étrangers, des laboratoires publics ou privés. 


\title{
Renal injury at first presentation as a predictor for poor outcome in severe paracetamol poisoning referred to a liver transplant unit
}

\author{
N. Pakravan • K. J. Simpson • W. S. Waring • \\ C. M. Bates • D. N. Bateman
}

Received: 22 July 2008 / Accepted: 5 October 2008 / Published online: 29 October 2008

(C) Springer-Verlag 2008

\begin{abstract}
Background Paracetamol poisoning remains a leading cause of morbidity and mortality. Identifying indices of poor prognosis at first presentation is key to both improving clinical care and determining targets for intervention. Renal failure is a feature of severe paracetamol poisoning. The aim of this study was to investigate the relationship between renal function (serum creatinine, $\mathrm{Cr}$ ) at first hospital presentation and time of tertiary referral to outcomes in severe paracetamol poisoning.

Methods This was a retrospective cohort analysis of patients referred to the Scottish Liver Transplant Unit due to paracetamol poisoning between 1992 and 2004. The relation between degree of renal injury and outcomes, including worst prothrombin time, Kings College Hospital Criteria (KCHC) and death were examined. The effects of age, nature (single or multiple) and stated size of overdose, hepatic enzyme induction (gamma-glutamyl transpeptidase, GGT), degree of liver injury (aspartate aminotransferase, prothrombin time), blood pressure and renal injury were assessed.

Results Data from 522 patients were included. Renal impairment $(\mathrm{Cr}>120 \mathrm{mmol} / \mathrm{l})$ was present in $48.8 \%$ of patients with
\end{abstract}

\footnotetext{
N. Pakravan · W. S. Waring • D. N. Bateman $(\triangle)$

National Poisons Information Service Edinburgh (Scottish

Poisons Information Bureau), The Royal Infirmary of Edinburgh,

51 Little France Crescent,

Edinburgh EH16 4SA, UK

e-mail: nick.bateman@luht.scot.nhs.uk
}

K. J. Simpson • C. M. Bates

Scottish Liver Transplant Unit, Royal Infirmary of Edinburgh,

Edinburgh, UK

N. Pakravan

University of Edinburgh,

Edinburgh, UK liver injury at time of first presentation. Creatinine at first admission predicted poorer outcome in terms of worse prothrombin time, KCHC and death $(p<0.001)$. Associated risk factors for renal dysfunction included later presentation, staggered ingestion, increased age, hypotension and elevated GGT at first admission.

Conclusions Creatinine at first admission appears to be a predictor of poor outcome in paracetamol overdose. A better understanding of mechanisms involved in causing renal dysfunction may offer potential therapeutic targets for improving outcome in this common poisoning.

Keywords First presentation - Paracetamol poisoning . Predictors of outcome $\cdot$ Renal dysfunction $\cdot$ Risk factors

\section{Introduction}

Paracetamol is one of the commonest medications used in overdose in developed countries [1,2]. Intravenous acetylcysteine is an effective antidote if administered sufficiently early after ingestion. A variety of treatment guidelines are in existence worldwide, but in the UK patients are grouped as "normal" or "high risk" depending on their history of risk factors and paracetamol concentrations [3]. Despite this, paracetamol poisoning is responsible for around 200 deaths annually in the UK alone [1, 4, 5]. Early markers of poor outcome are important both for acute physicians and liver units. Of particular interest is that while high doses of paracetamol are capable of causing both hepatic necrosis and renal tubular necrosis [6-9], renal failure is less common than liver failure after paracetamol overdose and has been reported in less than $1 \%$ of all patients [6]. The occurrence of renal failure is greater in more severely poisoned patients and is often observed in those that develop major liver injury 
$[7,10]$. Less commonly, renal failure is seen as an isolated manifestation of paracetamol toxicity $[8,9,11]$.

The King's College Hospital Criteria (KCHC) for liver transplantation [12] are widely used to predict outcome in more severely poisoned patients in liver units. Despite this, comparatively little is known about the prognostic value of investigations performed at first admission to hospital after severe poisoning. We hypothesised that since renal failure is an important component of the syndrome of severe paracetamol toxicity, elevated creatinine concentrations at the time of first admission or at the time of tertiary referral might indicate more severe paracetamol poisoning and poorer prognosis in those transferred to a liver unit. We also wished to explore the relationship between other known risk factors for liver injury and renal injury in this context.

\section{Methods}

\section{Data collection}

The Scottish Liver Transplant Unit (SLTU) is a tertiary referral centre for Scotland and part of Northern Ireland, providing clinical management of patients with severe liver disease and patients that require liver transplantation. Patients referred with liver damage due to paracetamol overdose were identified from a database maintained within the SLTU that contains information on clinical and laboratory variables and outcomes for patients referred to the Unit. Approval for this retrospective anonymised case study was received from the Local Ethics Committee. Referrals to the Unit from other hospitals between 1992 and 2004, including those due to severe paracetamol-induced liver damage, were accounted for, with the vast majority coming from Scotland. Available data at the time of initial referral to SLTU included age, gender, stated dose ingested, interval between ingestion and presentation to hospital, plasma paracetamol concentration, the presence of hypotension (systolic blood pressure $<100 \mathrm{mmHg}$ ), serum creatinine $(\mathrm{Cr})$, alanine transaminase (ALT) activity, gamma-glutamyl transpeptidase (GGT) activity and prothrombin time (PT) at time of admission to referring hospital and to SLTU. Additional data were worst recorded PT and clinically relevant outcome data: liver transplant, requirement for haemodialysis, intensive care unit (ITU) admission and death. Admission to ITU was determined by necessity for ventilation.

\section{Data analyses}

Ingestions at a single time-point, or within a 2-h period, were considered to be an acute ingestion, whereas ingestion at multiple related time-points or during an interval of more than $2 \mathrm{~h}$ was considered a staggered overdose. Acute ingestions were grouped by interval between overdose and first presentation to hospital: $\leq 24,>24-48$ and $>48 \mathrm{~h}$. Renal function was categorised in a clinical manner as normal $(\mathrm{Cr} \leq 120 \mu \mathrm{mol} / \mathrm{l})$, mild impairment $(120<\mathrm{Cr} \leq$ $180 \mu \mathrm{mol} / \mathrm{l})$, moderate impairment $(180<\mathrm{Cr}<300 \mu \mathrm{mol} / \mathrm{l})$ and severe impairment $(\mathrm{Cr} \geq 300 \mu \mathrm{mol} / \mathrm{l})$. Severe liver injury was determined by PT, and a PT of $>25 \mathrm{~s}$ was used as an arbitrary clinically relevant cut off.

A receiver operator characteristic was used to examine the relationship between serum $\mathrm{Cr}$ concentration at the time of referral to SLTU and the subsequent need for haemodialysis (or other outcome measure).

In a dataset of this type, in which clinical sampling was not pre-determined by protocol, it was not surprising that some data were absent. Data for analysis were therefore included for all patients in whom these were available for each time period. The data are presented as mean \pm standard error of the mean (SEM), with proportions where appropriate. Between-group comparisons were made using Student's $t$ test for independent samples and Pearson's Chi square tests. Multiple comparisons analysis for continuous data was made by one-way analysis of variance (ANOVA) with Post-Hoc Bonferroni correction.

\section{Results}

In the period of this study, 522 patients with paracetamol overdose were admitted to the SLTU from referring hospitals. There were approximately equal numbers of men $(49.2 \%)$ and women $(50.8 \%)$, and the median age of the patients was 34.0 [interquartile range (IQR) 26.0-53.0] years. Full biochemical data for analysis were available at admission for 444 patients at the referral hospital and for 507 patients in the SLTU. Overall mortality was $28.2 \%$ (147/522), and $34.2 \%$ of patients required dialysis.

At first presentation to the referring hospital, 69.1\% (320/463) of patients for whom data were available had significant impairment of liver function, as reflected by the PT (Table 1). Of this group with liver injury, 156 (48.8\%) had a serum $\mathrm{Cr}$ suggesting some degree of renal injury $(\mathrm{Cr}>120 \mathrm{mmol} / \mathrm{l})$. At first presentation, 39.4\% (182/ 463) of all patients, with and without PT elevation, had data compatible with renal injury (18.6\% mild, $11.9 \%$ moderate and $8.9 \%$ severe renal impairment).

Abnormalities in liver function occurred more rapidly than those in renal function, thus ALT and PT were generally abnormal at initial presentation (Table 2). By the time patients were admitted to the SLTU, 90\% had developed significant liver injury, while $16.8 \%$ had mild, $20.9 \%$ moderate and $16.2 \%$ severe renal injury (Table 1 ). Overall, $96.6 \%$ of patients developed significant liver injury (worst PT $\geq 25 \mathrm{~s}$ ). 
Table 1 Severity of liver and renal impairment at presentation to the referring hospital and to the Scottish Liver Transplant Unit tertiary centre

\begin{tabular}{|c|c|c|c|c|c|c|c|c|}
\hline \multirow[t]{3}{*}{ Groups according to renal and liver function } & \multicolumn{4}{|c|}{ Referring hospital $(n=463)$} & \multicolumn{4}{|c|}{ SLTU $(n=507)$} \\
\hline & \multicolumn{2}{|c|}{$\begin{array}{l}\mathrm{PT} \geq 25 \mathrm{~s} \\
\text { (with liver injury) }\end{array}$} & \multicolumn{2}{|c|}{$\begin{array}{l}\mathrm{PT}<25 \mathrm{~s} \\
\text { (no liver injury) }\end{array}$} & \multicolumn{2}{|c|}{$\begin{array}{l}\mathrm{PT} \geq 25 \mathrm{~s} \\
\text { (with liver injury) }\end{array}$} & \multicolumn{2}{|c|}{$\begin{array}{l}\mathrm{PT}<25 \mathrm{~s} \\
\text { (no liver injury) }\end{array}$} \\
\hline & $n$ & $\%$ & $n$ & $\%$ & $n$ & $\%$ & $n$ & $\%$ \\
\hline Normal renal function, $\mathrm{Cr} \leq 120 \mu \mathrm{mol} / 1$ & 164 & 35.4 & 117 & 25.3 & 209 & 41.2 & 26 & 5.1 \\
\hline Mild renal dysfunction, $120<\mathrm{Cr} \leq 180 \mu \mathrm{mol} / 1$ & 69 & 14.9 & 17 & 3.7 & 81 & 16.0 & 3 & 0.6 \\
\hline Moderate renal dysfunction, $180<\mathrm{Cr}<300 \mu \mathrm{mol} / 1$ & 48 & 10.4 & 7 & 1.5 & 97 & 19.1 & 9 & 1.8 \\
\hline Severe renal dysfunction, $\mathrm{Cr} \geq 300 \mu \mathrm{mol} / 1$ & 39 & 8.4 & 2 & 0.4 & 70 & 13.8 & 12 & 2.4 \\
\hline Total & 320 & 69.1 & 143 & 30.9 & 457 & 90.1 & 50 & 9.9 \\
\hline
\end{tabular}

SLTU, Scottish Liver Transplant Unit; PT, prothrombin time (s); Cr, creatinine; $n$, number of subjects with available data.

Mortality rates were highest in patients that first presented to hospital more than $24 \mathrm{~h}$ after ingestion $(p<0.01)$. Delay in presentation was also associated with an increase in poor prognosis according to the KCHC. Thus, in the group who presented after $24 \mathrm{~h}, 33.6 \%(49 / 146)$ developed poor prognosis according to the $\mathrm{KCHC}$ as compared to $17.6 \%$ $(31 / 176)$ of patients presenting within $24 \mathrm{~h} \quad(p<0.01$ (Table 2). Mortality in the group with staggered overdose was significantly worse $(34.4 \%, 44 / 128)$ than in those with a single overdose $(21.5 \%, 76 / 354)$. There was also no significant difference in the stated dose of ingested paracetamol in the group with single and staggered overdose (staggered overdose: $30 \pm 2.3 \mathrm{~g}$, single overdose: $33.5 \pm 5 \mathrm{~g}$ ).

Creatinine concentration at first admission ( referral $\mathrm{Cr}$ ) was significantly higher in patients presenting more than $24 \mathrm{~h}$ after ingestion $(155.8 \pm 7.9 \mu \mathrm{mol} / \mathrm{l})$ than in those presenting within $24 \mathrm{~h}(98.3 \pm 3.7 \mu \mathrm{mol} / \mathrm{l})(p<0.0001$; Table 2$)$, which is in keeping with deteriorating renal function. There was no age

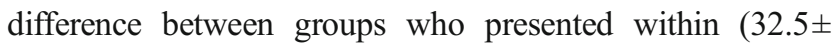

0.9 years $)$ or after $24 \mathrm{~h}(34.6 \pm 1.0$ years $)$. Referral $\mathrm{Cr}$ following staggered overdose $(177.9 \pm 12.0 \mu \mathrm{mol} / \mathrm{l}, n=116)$ was significantly higher $(p<0.0001)$ than that in acute overdose patients who presented within $24 \mathrm{~h}$ of ingestion $(98.3 \pm 3.7 \mu \mathrm{mol} / \mathrm{l}, n=161)$, but was similar to that in those presenting more than $24 \mathrm{~h}$ (Table 2). Patients with staggered overdose were significantly older $(38.2 \pm 1.0$ years $)$ than those with a single overdose (33.7 \pm 0.6 years).

Data on the highest $\mathrm{Cr}$ during inpatient stay was not available to us, however $38.4 \%$ of patients developed moderate and severe renal injury (worst $\mathrm{Cr}>180 \mu \mathrm{mol} / \mathrm{l}$ ) as judged on samples available at admission to either the referring hospital or the SLTU. Stated paracetamol dose in acute ingestions did not correlate with risk of renal impairment as judged by $\mathrm{Cr}$ at time of referral to SLTU $(\mathrm{Cr} \leq 120 \mu \mathrm{mol} / \mathrm{l}: 34 \pm 2 \mathrm{~g} ; 120<\mathrm{Cr} \leq 180 \mu \mathrm{mol} / \mathrm{l}: 28 \pm 2 \mathrm{~g}$; $80<\mathrm{Cr}<300 \mu \mathrm{mol} / 1: 39 \pm 3 \mathrm{~g} ; \geq 300 \mu \mathrm{mol} / \mathrm{l}: 27 \pm 3 \mathrm{~g}$ ).

Factors associated with more severe renal impairment at the time of transfer to SLTU were increased age $(p<0.0001)$,

Table 2 Laboratory and clinical variables with respect to the interval between single acute paracetamol ingestion and first presentation to hospital in paracetamol overdose

\begin{tabular}{lllll}
\hline Time from ingestion to presentation & $\leq 24 \mathrm{~h}(n)$ & $>24, \leq 8 \mathrm{~h}(n)$ & $>48 \mathrm{~h}(n)$ & Significance level $(p)$ \\
\hline Interval (h) & $15.2 \pm 0.5(176)$ & $37.4 \pm 0.8(104)$ & $66.6 \pm 2.8(42)$ & \\
Referral Cr ( $\mu \mathrm{mol} / \mathrm{l})$ & $98.3 \pm 3.7(161)$ & $140.6 \pm 7.9(94)$ & $192.6 \pm 18.2(39)$ & $<0.0001^{\mathrm{a}}$ \\
Referral PT (s) & $29.9 \pm 1.7(166)$ & $45.4 \pm 2.1(101)$ & $65.0 \pm 6.0(39)$ & $<0.0001^{\mathrm{a}}$ \\
Referral ALT (IU/1) & $1960 \pm 264(147)$ & $5524 \pm 520(75)$ & $7887 \pm 875(30)$ & $<0.0001^{\mathrm{b}}$ \\
Worst PT (s) & $62.8 \pm 2.9(173)$ & $67.3 \pm 3.4(104)$ & $77.1 \pm 6.4(42)$ & $\mathrm{NS}$ \\
Dialysis (\%) & $19.5(34 / 174)$ & $44.2(46 / 104)$ & $34.1(14 / 41)$ & $<0.0001^{\mathrm{c}}$ \\
KCHC poor prognosis (\%) & $17.6(31 / 176)$ & $36.5(38 / 104)$ & $26.2(11 / 42)$ & $<0.01^{\mathrm{d}}$ \\
Mortality (\%) & $15.3(27 / 176)$ & $28.3(30 / 104)$ & $23.8(10 / 42)$ & $<0.05^{\mathrm{d}}$
\end{tabular}

$n$, Number of subjects with available data; KCHC, King's College Hospital Criteria; ALT, alanine aminotransferase; NS, non-significant Values are presented as the mean \pm standard error of the mean (SEM)

${ }^{\text {a }}$ Serum $\mathrm{Cr}$ and PT higher in patients presenting $>24 \mathrm{~h}(p<0.0001)$. Cr and PT were also higher in $>48 \mathrm{~h}$ group compared to $>24-48 \mathrm{~h}(p<0.0001)$.

${ }^{\mathrm{b}}$ ALT was higher in patients presenting $>24 \mathrm{~h}(p<0.0001)$ compared to those presenting $\leq 24 \mathrm{~h}$. The ALT was also higher in $>48 \mathrm{~h}$ group compared to $>24-48 \mathrm{~h}$ group $(p<0.05)$.

${ }^{\mathrm{c}}$ Dialysis requirement was significantly higher in patients presenting $>24 \mathrm{~h}(p<0.0001)$.

${ }^{\mathrm{d}} \mathrm{KCHC}$ poor prognosis and mortality were significantly higher in patients presenting $>24 \mathrm{~h}(p<0.01$ for KCHC poor prognosis, $p<0$. 05 for mortality). 
hypotension at admission to referral hospital or at transfer $(p<0.0001)$ and interval between ingestion and delay to first presentation to hospital $(p<0.0001)$ (Table 3). Patients with more severe renal injury also had a higher GGT at first presentation, and acidosis was also more common in renal injury $(p<0.0001)$. A higher proportion of patients with severe renal impairment had taken a staggered overdose (Table 3).

\section{Discussion}

Paracetamol poisoning is a common clinical problem, and early identification of patients with more severe poisoning is key to improving outcomes. Present tools for riskstratification are predominantly based on paracetamol concentration timed after ingestion and are targeted at reducing liver injury, usually as rises in hepatic transami- nase $[6,13]$. This approach is dependant on an accurate history and a single ingestion time point. Accuracy beyond $15 \mathrm{~h}$ after ingestion is less certain. Thus, research that is aimed at improving outcome prediction based on paracetamol concentration [14] may not be applicable to many in this cohort of more severe poisoning, where patients present late or with staggered ingestion. In addition to the factors we report here, previous work has identified hypophosphataemia and phosphaturia as potential early markers of more severe toxicity at first presentation [15]. We have not studied these, as these measurements were not routinely carried out.

Although renal failure is a recognised complication of paracetamol toxicity, the underlying mechanisms are poorly understood. Toxic metabolites of paracetamol are generated by local metabolism in the kidney and may cause acute tubular necrosis, particularly in conditions associated with glutathione depletion [16]. Even in the absence of acute

Table 3 Clinical characteristics at first admission and outcomes in patients with paracetamol overdose grouped by renal function at the time of tertiary admission

\begin{tabular}{|c|c|c|c|c|c|}
\hline Renal impairment $\mathrm{Cr}(\mu \mathrm{mol} / \mathrm{l})$ & $\begin{array}{l}\text { Normal: } \\
\mathrm{Cr} \leq 120\end{array}$ & $\begin{array}{l}\text { Mild: } \\
120<\mathrm{Cr} \leq 180\end{array}$ & $\begin{array}{l}\text { Moderate: } \\
180<\mathrm{Cr}<300\end{array}$ & $\begin{array}{l}\text { Severe: } \\
\mathrm{Cr} \geq 300\end{array}$ & $\begin{array}{l}\text { Significance } \\
\text { level }(p)\end{array}$ \\
\hline$n(\%)$ & $239(46.8 \%)$ & $84(16.4 \%)$ & $106(20.7 \%)$ & $82(16.0 \%)$ & \\
\hline Male/female & $102 / 137$ & $45 / 39$ & $62 / 44$ & $42 / 40$ & \\
\hline Age (years) & $32 \pm 1$ & $38 \pm 2$ & $39 \pm 1$ & $39 \pm 1$ & $<0.0001^{\mathrm{a}}$ \\
\hline Staggered overdose (\%) & $18.5 \%(n=43 / 2333)$ & $28.5 \%(n=22 / 78)$ & $26.9 \%(n=25 / 93)$ & $50.7 \%(n=36 / 71)$ & $<0.0001^{\mathrm{b}}$ \\
\hline Hypotension at first admission (\%) & $3.9 \%(n=9 / 239)$ & $18.1 \%(n=15 / 83)$ & $32.0 \%(n=33 / 103)$ & $32.1 \%(n=25 / 78)$ & $<0.0001^{\mathrm{c}}$ \\
\hline Delay to first admission (h) & $25 \pm 1(n=179)$ & $28 \pm 2(n=56)$ & $36 \pm 3(n=65)$ & $43 \pm 5(n=37)$ & $<0.0001^{\mathrm{d}}$ \\
\hline First PT (s) & $37 \pm 9(n=211)$ & $42 \pm 2.8(n=77)$ & $51 \pm 3.2(n=92)$ & $59 \pm 4(n=75)$ & $<0.0001^{\mathrm{e}}$ \\
\hline First GGT (u/l) & $82 \pm 8(n=144)$ & $155 \pm 19(n=57)$ & $164 \pm 18(n=57)$ & $238 \pm 24(n=51)$ & $<0.0001^{\mathrm{f}}$ \\
\hline First $\left[\mathrm{H}^{+}\right](\mathrm{mmol} / 1$ & $42 \pm 1(n=149)$ & $53 \pm 3(n=58)$ & $61 \pm 4(n=64)$ & $54 \pm 3(n=54)$ & $<0.0001^{\mathrm{g}}$ \\
\hline First K (mmol/l) & $3.9 \pm 0.05(n=222)$ & $4.2 \pm 1.0(n=75)$ & $4.5 \pm 1.0(n=100)$ & $4.8 \pm 0.1(n=73)$ & $<0.0001^{\mathrm{h}}$ \\
\hline Worst PT (s) & $59 \pm 2(n=235)$ & $73 \pm 5(n=84)$ & $82 \pm 5(n=106)$ & $75 \pm 5(n=81)$ & $<0.0001^{\mathrm{k}}$ \\
\hline ITU stay (days) & $1.4 \pm 0.2(n=237)$ & $2.5 \pm 0.4(n=83)$ & $4.7 \pm 1.0(n=104)$ & $4.1 \pm 0.6(n=80)$ & $<0.0001^{\mathrm{m}}$ \\
\hline Mortality (\%) & $8.8(n=21 / 239)$ & $32.1(n=27 / 84)$ & $47.2(n=50 / 106)$ & $51.2(n=42 / 82)$ & $<0.0001^{\mathrm{n}}$ \\
\hline
\end{tabular}

$n$, Number of subjects with available data; ITU, Intensive Care Unit

${ }^{a}$ Patients with any renal dysfunction were older $(p<0.0001)$. Those with moderate and severe dysfunction were older than those with mild dysfunction $(p<0.0001)$

${ }^{\mathrm{b}}$ Staggered overdose was more common in those with severe renal dysfunction than in those with normal renal function $(p<0.0001)$ and mild or moderate renal dysfunction $(p<0.01)$

${ }^{\mathrm{c}}$ Renal dysfunction at first admission was more common in those with hypotension $(p<0.0001)$. Severe dysfunction was more common than normal $(p<0.0001)$ or mild dysfunction $(p<0.01)$

${ }^{\mathrm{d}}$ Patients with moderate and severe renal dysfunction presented later than those with normal renal function $(p<0.0001)$. Patients with severe renal dysfunction presented later than mild dysfunction $(p<0.01)$

${ }^{\mathrm{e}}$ Significant intergroup difference in referral PT $(p<0.01)$. Referral PT was higher in patients with moderate and severe renal function than in those with normal $(p<0.01)$. Referral PT was less in mild than severe renal function $(p<0.01)$

${ }^{\mathrm{f}}$ GGT was lower in patients with normal renal function $(p<0.0001)$. GGT was higher in severe than mild $(p<0.01)$ or moderate renal function $(p<0.05)$

${ }^{\mathrm{g}}$ Referral $\left[\mathrm{H}^{+}\right]$in group with normal renal function was significantly lower than that in mild $(p<0.01)$, moderate $(p<0.0001)$ and severe $(p<0.01)$ renal dysfunction

${ }^{\mathrm{h}}$ Referral $\mathrm{K}$ in the group with normal function was significantly lower than that in moderate and severe renal dysfunction $(p<0.0001$. Referral $\mathrm{K}$ in the group with mild dysfunction was significantly lower than that in severe renal dysfunction $(p<0.0001)$

${ }^{\mathrm{k}}$ Worst PT in normal group was significantly lower than mild $(p<0.05)$, moderate $(p<0.0001)$, or severe renal dysfunction $(p<0.05)$

${ }^{\mathrm{m}}$ Patients with moderate and severe renal dysfunction stayed longer in the intensive care unit (ITU) than those with normal renal function $(p<0.0001$ and $p<0.01$, respectively)

${ }^{n}$ Mortality in the group with normal renal function was significantly lower those with mild, moderate and severe renal dysfunction $(p<0.0001)$.

Those with mild renal dysfunction had lower mortality than those with moderate or severe renal dysfunction $(p<0.05)$ 
renal failure, paracetamol ingestion is associated with dosedependent changes in electrolyte transport, suggesting a direct pharmacological action of paracetamol on renal tubular function [17, 18]. Risk factors, such as glutathione depletion in the kidney, concomitant ingestion of nephrotoxic substances, dehydration at presentation, chronic excessive overdose of paracetamol and pre-existing liver and renal insufficiency may all increase the risk of renal injury after paracetamol overdose [19].

As expected, most patients in the current series requiring tertiary referral after paracetamol overdose had evidence of acute liver dysfunction defined by $\mathrm{PT} \geq 25 \mathrm{~s}$ (96.6\%). Our study found that within this patient population, there was a higher prevalence of renal impairment $(38.4 \%$; $\mathrm{Cr}>$ $180 \mu \mathrm{mol} / \mathrm{l}$ at admission to either hospital) than has been previously described in severe paracetamol poisoning $[6,20]$. This is almost certainly due to the highly selected patient population. Importantly, these data indicate that $\mathrm{Cr}$ at the time of first admission in this cohort was an important predictor of developing poor prognosis according to the $\mathrm{KCHC}$. The data also show that groups with more severe renal injury, both at first presentation and tertiary transfer, had other markers of worse outcome, as indicated by higher PT, longer stay in ITU, greater need for dialysis and higher mortality (Tables 1 and 3). The vast majority of patients stated they had taken doses regarded as potentially hepatotoxic, although we could not find a dose-response relationship between stated dose and nephrotoxicity. We have previously reported on a very small number in this case series in whom paracetamol dose appeared to be below the standard plasma concentration-time curves [21].

Renal dysfunction was more severe with later presentation, in patients with hypotension at admission, those who were older and those who had a high initial GGT. Renal dysfunction was also worse in those who had taken a staggered overdose. Our findings are similar to those reported in children who present to hospital after paracetamol overdose: a prolonged interval between ingestion and presentation to hospital and renal impairment were both associated with poorer prognosis [22].

To explore this data further, a receiver operating characteristic (ROC) curve was constructed for referral $\mathrm{Cr}$ concentration as a predictor of poor prognosis according to the $\mathrm{KCHC}$ (Fig. 1). The area under the curve was $74.3 \%$ [95\% confidence interval (CI) $70.1-78.1 \%, p=0.0001$ compared to the $50 \%$ line by the $z$ test). This plot indicated that in this cohort a $\mathrm{Cr}>123 \mu \mathrm{mol} / \mathrm{l}$ at presentation to the referring hospital had a sensitivity of $71.3 \%$ (95\% CI $62.7-$ $78.9 \%$ ) and specificity of $73.3 \%$ (95\% CI $68.3-77.9 \%)$ for a poor prognosis according to the $\mathrm{KCHC}$ during the hospital stay. A serum $\mathrm{Cr}$ of $123 \mu \mathrm{mol} / 1$ is very close to the upper limit of normal, and while this potential tool needs validation in other similar large cohorts, it has the

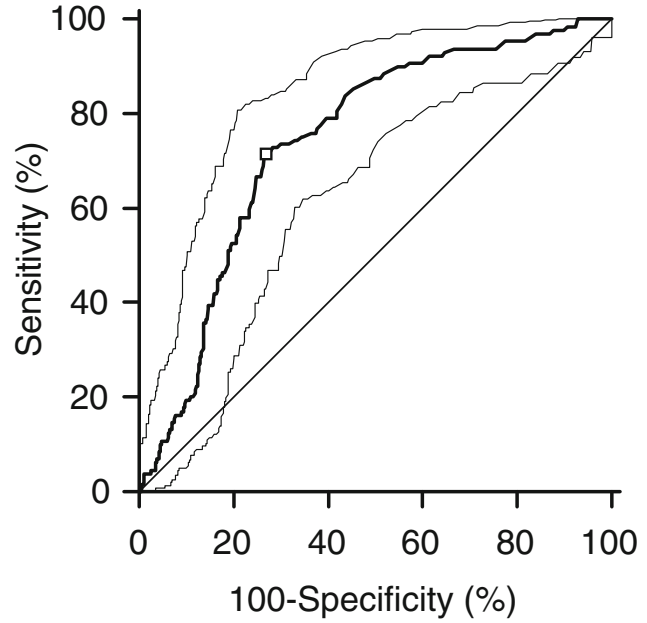

Fig. 1 The receiver operating characteristic (ROC) curve for referral creatinine versus "King's College poor outcome" area under the ROC curve $(\mathrm{AUC})=74.3 \%[95 \%$ confidence interval (CI) $70.1-78.1 \%$, significance level $p=0.0001$ (versus 0.5 line by $z$ test)]. The most "accurate' predictor" is referral creatinine $>123 \mu \mathrm{mol} / 1$, sensitivity $=$ $71.3 \%$ (95\% CI $62.7-78.9 \%)$ and specificity $=73.3 \%$ (95\% CI $68.3-$ $77.9 \%)$

attraction of simplicity as a clinical marker for the early detection of patients at greatest risk.

These data come from a large single UK centre and may therefore not be representative of other liver units. Other factors not tested in this study include deprivation, which has also been found to be associated with poor outcomes in Scotland [23] and might be a confounder not generally applicable in other patient groups.

The use of serum $\mathrm{Cr}$ as a risk factor thus needs to be tested independently by others. Nevertheless, the present data underpin the importance of prompt hospital referral and the administration of acetylcysteine, which has been shown to be most effective when given within the first $8-12 \mathrm{~h}$ after paracetamol ingestion [13]. It is increasingly recognised that patients presenting to hospital after staggered overdose are at substantially increased risk than those after acute single ingestion. This is reflected in the present data, where staggered overdoses comprise a high proportion of patients referred to the SLTU. Thus, a careful history in which close attention is paid to $\mathrm{Cr}$ concentration, the presence of hypotension and GGT activity should allow earlier identification of patients who are at greater risk of poor outcome. Better public information on the need for urgent therapy and avoidance of excess therapeutic doses may also be warranted.

In conclusion, while renal impairment is relatively uncommon after mild to moderate paracetamol overdose, it was a common complication in the patients of our study cohort who were referred to a tertiary centre with severe paracetamol toxicity, and it was identifiable in a majority of high-risk patients in this cohort at first 
presentation. Important clinical factors predicting poor outcome were: presentation to hospital $>24 \mathrm{~h}$ after ingestion, elevated $\mathrm{Cr}$ concentration at the time of first presentation, hypotension, staggered overdose and raised GGT. Renal dysfunction at first presentation appears to be an important predictor of subsequent liver toxicity and death in this group. Further work is required to explore whether more subtle markers of renal impairment might allow better risk-stratification in patients that present to hospital after paracetamol overdose.

Acknowledgements We gratefully acknowledge the assistance of Janice Davidson who maintains the database used for this study

\section{References}

1. Hawton K, Fagg J (1992) Trends in deliberate self poisoning and self injury in Oxford, 1976-90. Br Med J 304:1409-1411

2. Daley FFS, Fountain JS, Murray L, Graudins A, Buckley NA (2008) Guidelines for the management of paracetamol poisoning in Australia and New Zealand- explanation and elaboration. Med J Aust 188:296-301

3. Anonymous (2008) Poisoning. British National Formulary 55 (March 2008). RPS Publishing, London

4. Morgan OW, Griffiths C, Majeed A (2007) Interrupted time-series analysis of regulations to reduce paracetamol (acetaminophen) poisoning. PLoS Med 4:e105. doi:10.1371/journal.pmed.0040105

5. Bray GP (1993) Liver failure induced by paracetamol. Br Med J 306:157-158

6. Prescott LF (1983) Paracetamol overdosage. Pharmacological considerations and clinical management. Drugs 25:290-314

7. Boyer TD, Rouff SL (1971) Acetaminophen-induced hepatic necrosis and renal failure. JAMA 218:440-441

8. Curry RW Jr, Robinson JD, Sughrue MJ (1982) Acute renal failure after acetaminophen ingestion. JAMA 247:1012-1014

9. Kleinman JG, Breitenfield RV, Roth DA (1980) Acute renal failure associated with acetaminophen ingestion: report of a case and review of the literature. Clin Nephrol 14:201-205
10. Blakely P, McDonald BR (1995) Acute renal failure due to acetaminophen ingestion: a case report and review of the literature. J Am Soc Nephrol 6:48-53

11. Kher K, Makker S (1987) Acute renal failure due to acetaminophen ingestion without concurrent hepatotoxicity. Am J Med $82: 1280-1281$

12. O'Grady JG, Alexander GJ, Hayllar KM, Williams R (1989) Early indicators of prognosis in fulminant hepatic failure. Gastroenterology 97:439-445

13. Smilkstein MJ, Knapp GL, Kulig KW, Rumack BH (1988) Efficacy of oral N-acetylcysteine in the treatment of acetaminophen overdose. Analysis of the national multicenter study (1976 to 1985). N Engl J Med 319:1557-1562

14. Sivilotti ML, Yarema MC, Juurlink DN, Good AM, Johnson DW (2005) A risk quantification instrument for acute acetaminophen overdose patients treated with N-acetylcysteine. Ann Emerg Med 46:272-274

15. Jones AF, Harvey JM, Vale JA (1989) Hypophosphataemia and phosphaturia in paracetamol poisoning. Lancet 2:608-609

16. Mitchell JR, McMurtry RJ, Statham CN, Nelson SD (1977) Molecular basis for several drug-induced nephropathies. Am J Med 62:518-526

17. Trumper L, Girardi G, Elias MM (1992) Acetaminophen nephrotoxicity in male Wistar rats. Arch Toxicol 66:107-111

18. Pakravan N, Bateman DN, Goddard J (2007) Effect of acute paracetamol overdose on changes in serum and urine electrolytes. Br J Clin Pharmacol 64:824-832

19. von Mach MA, Hermanns-Clausen M, Koch I et al (2005) Experiences of a poison center network with renal insufficiency in acetaminophen overdose: an analysis of 17 cases. Clin Toxicol (Phila) 43:31-37

20. Boutis K, Shannon M (2001) Nephrotoxicity after acute severe acetaminophen poisoning in adolescents. $\mathrm{J}$ Toxicol Clin Toxicol 39:441-445

21. Beer C, Pakravan N, Hudson M et al (2007) Liver unit admission following paracetamol overdose with concentrations below current UK treatment thresholds. Q J Med 100:93-96

22. Mahadevan SB, McKiernan PJ, Davies P, Kelly DA (2006) Paracetamol induced hepatotoxicity. Arch Dis Child 91:598-603

23. Gorman DR, Bain M, Inglis JHC, Murphy D, Bateman DN (2007) How has legislation restricting paracetamol pack size affected patterns of deprivation related inequalities in self-harm in Scotland? Public Health 121:45-50 